\title{
Morphological Priming Effect: The Role of Surface Frequency
}

\author{
Fanny Meunier \\ Medical Research Council-CBU, Cambridge, United Kingdom \\ and \\ Juan Segui \\ CNRS and Université René Descartes, Paris, France
}

\begin{abstract}
Two cross-modal experiments were conducted to investigate the format of lexical representation of suffixed derived words and their stems. The results show that only low frequency suffixed words (as opposed to high frequency suffixed words) yield a full priming effect of their stems. By contrast, a stem (e.g., travail) does not fully prime words belonging to the same morphological family (e.g., travailleur), although it primes high frequency suffixed words more than it does low frequency words. To account for these findings we propose a model in which the stem and high frequency affixed words are represented both as full forms and as decomposed morphemes while low frequency affixed words are represented only in a decomposed form. (๑) 1999 Academic Press
\end{abstract}

Key Words: suffixed word; cross-modal priming; lexical frequency.

The purpose of our work is to provide information about the lexical representation of morphologically complex words. In the experiments reported in this paper, we focused on the role of surface frequency in processing derived words and on the way these words are lexically represented.

The topic of the lexical representation of morphologically complex words has generated many studies, most of them using a priming paradigm. The morphological priming effect, as opposed to formal- or semantic-priming effects, between a morphologically complex word and its stem, and between the stem and affixed words derived from this stem, is now well established

This research was supported by a grant of the Foundation Fyssen to the first author. We thank Sami Boudelaa and Elsa Spinelli for their help and suggestions.

Correspondence and reprint requests concerning this article should be addressed to Fanny Meunier, Cognition and Brain Sciences Unit, Medical Research Council, 15 Chaucer Road, Cambridge CB2 2EF, UK. E-mail: fanny.meunier@mrc-cbu.cam.ac.uk. 
(see Drews, 1996, for a review). One variant of the priming paradigm is cross-modal priming, in which subjects hear a prime word and, at its acoustic offset, see a target item. Subjects must make a lexical decision on the visually presented word or nonword. The advantage of this paradigm is that it taps directly into the level of central representation. Cross-modal priming effects are supposed to reflect repeated access to a lexical representation shared by prime and target (Marslen-Wilson, Tyler, Waksler, \& Older, 1994). One can argue that only a full priming effect, one that does not differ from the identity priming effect, would reflect repeated access to a single lexical representation, whereas a morphological priming effect may only reflect links and spreading activation within the lexicon between different representations (Fowler, Napps, \& Feldman, 1985; Kempley \& Morton, 1982). A first point that we want to explore in our experiments is whether a derived word primes its stem as much as a stem primes itself, and if a stem primes a derived word belonging to the same morphological family as much as a derived word primes itself.

Two extreme views of how morphologically complex words are processed and represented have been proposed. The first posits a prelexical decomposition of each word into its constituent morphemes with morphemic lexical representations (e.g., Taft \& Forster, 1975). The other extreme claims that morphologically complex words are processed and represented as monomorphemic words using their full form (e.g., Butterworth, 1983). The majority of recent theoretical proposals, however, are between these two extreme positions in the sense that they assume two different formats of processing or representation of complex words: a decomposed format and a direct or fullform format (see Cutler \& McQueen, 1998, for a review). Important components of these models are the lexical factors that determine how a word is accessed, or what kind of representation is going to be activated. Several factors have been proposed: semantic transparency, cumulative frequency, productivity of the affix, and surface frequency (Frauenfelder \& Schreuder, 1992; Laudanna, Badecker, \& Caramazza, 1989; Laudanna \& Burani, 1985; Schreuder \& Baayen, 1995). It is on the latter component that we are going to focus. Although it has been proposed, it has not been shown empirically that the surface frequency of a derived word plays a role in the kind of relationship that this word has with its stem. In the experiments presented here, we investigate the role of the surface frequency of derived words in the relationship they have with their stem.

To summarize, the two experiments presented here were designed to answer three questions: (1) Does a derived word prime its stem as much as the stem itself?; (2) Does a stem prime a derived word as much as the derived word itself?; (3) Do these priming effects vary depending on the surface frequency of the derived word?

The experiments to be reported were conducted using the same linguistic material and procedure: one to test the priming effect between a derived word 
TABLE 1

Design and Sample Stimuli Used in Experiment 1

\begin{tabular}{lll}
\hline & Prime & Target \\
\hline Stem/stem & travail & travail \\
Derived LF/Stem & travailliste & travail \\
Derived HF/Stem & travailleur & travail \\
\hline
\end{tabular}

Note. LF: low frequency; HF: High frequency.

and its stem, and the other to test the reverse, the priming effect between a stem and an affixed word derived from this stem. The linguistic material selected consisted of triplets of words belonging to the same morphological family: a free stem and two suffixed words. One of the suffixed words had a low surface frequency and the other a high surface frequency. They were chosen so that their lengths were comparable. The relationship between the suffixed words and their stem were semantically transparent.

\section{EXPERIMENT 1}

The aim of this experiment was to investigate whether a derived word fully primes its stem, and whether this priming effect depends on the frequency of the derived word. We compared the priming between a high surface frequency suffixed word and its stem and the priming between a low surface frequency suffixed word and its stem, to the priming obtained by a simple repetition of the stem.

\section{Method}

We selected 51 triplets of words, and constructed three experimental conditions that are presented in Table 1. Another 231 filler pairs were selected to construct three experimental lists, such that each subject saw a particular stem only once. Thirty French native speakers took part in the experiment.

\section{Results and Discussion}

Analyses of variance (ANOVA) were conducted on the reaction time data. We conducted analysis across both participants (F1) and items (F2). The data showed an error rate of $1 \%$. The results, listed in Table 2, are straightfor-

TABLE 2

Experiment 1: Lexical Decision RTs (ms) and Standard

Deviation $(S D)$

\begin{tabular}{lccc}
\hline & Stem/Stem & Derived HF/Stem & Derived LF/Stem \\
\hline RT (ms) & 488 & 516 & 492 \\
SD & 54 & 68 & 62 \\
\hline
\end{tabular}


TABLE 3

Design and Sample Stimuli Used in Experiment 2

\begin{tabular}{lll}
\hline & \multicolumn{1}{c}{ Prime } & Target \\
\hline Derived LF/Derived LF & travailliste & travailliste \\
Stem/Derived LF & travail & travailliste \\
Derived HF/Derived HF & travailleur & travailleur \\
Stem/Derived HF & travail & travailleur \\
\hline
\end{tabular}

ward. There was no difference between the identity condition and the condition where the prime is a suffixed word with a low frequency $(F 1(1,29)<$ $1 ; F 2(1,49)<1)$. This means that a stem is identified as fast when it is preceded by itself as when it is preceded by a low frequency word derived from it. In contrast, there is a significant difference between the identity condition and the condition where the prime is a high frequency suffixed word belonging to the same morphological family $(F 1(1,29)=17.05, p<$ $.001 ; F 2(1,49)=17.48, p<.001)$. A difference was also observed when the target is preceded by a low frequency word and when it is preceded by a high frequency word $(F 1(1,29)=9.82, p<.004 ; F 2(1,49)=9.01$, $p<.004)$.

This experiment shows that low surface frequency suffixed words prime their stem as much as stems prime themselves, but this is not the case for high frequency words. This could suggest that only low frequency suffixed words are recognized through a morphemic representation, whereas high frequency suffixed words are recognized through their own independent lexical representation. However, it should be kept in mind that this does not exclude the possibility that high frequency derived words are lexically represented twice: as a full form and as a morphemic form.

\section{EXPERIMENT 2}

The second experiment focused on the relation between stem and suffixed word. Does a stem prime affixed words as much as affixed words themselves, and does a stem prime a low frequency suffixed word in a different way than a high frequency suffixed word?

\section{Method}

The same linguistic material as in the previous experiment was used. The only difference was that the targets were the derived words, which meant we needed two identity conditions. Hence, the experiment included four experimental conditions as shown in Table 3. As each subject sees only one word of each morphological family, we constructed four experimental lists. Forty subjects from the same population that participated in Experiment 1 were tested. 
TABLE 4

Experiment 2: Lexical Decision RTs (ms) and Standard Deviation (SD)

\begin{tabular}{lcccc}
\hline & $\begin{array}{c}\text { Stem/ } \\
\text { Derived HF }\end{array}$ & $\begin{array}{c}\text { Derived HF/ } \\
\text { Derived HF }\end{array}$ & $\begin{array}{c}\text { Stem/ } \\
\text { Derived LF }\end{array}$ & $\begin{array}{c}\text { Derived LF/ } \\
\text { Derived LF }\end{array}$ \\
\hline RT (ms) & 563 & 526 & 642 & 571 \\
$S D$ & 88 & 81 & 119 & 115 \\
\hline
\end{tabular}

\section{Results and Discussion}

There was a $3 \%$ error rate. The results are presented in Table 4 . There is a difference between the identity conditions and the morphological conditions $(F 1(1,39)=51.36, p<.001 ; F 2(1,50)=48.78, p<.001)$. The amount of priming generated by the stem was lower for suffixed words than for the stem itself. There is also an effect of the frequency of the target $(F 1(1,39)$ $=64.93, p<.001 ; F 2(1,50)=43.05, p<.001)$ : High frequency words are identified faster than low frequency ones. Of more interest is the finding that type of priming (identity vs morphology) interacts with the frequency of the target $(F 1(1,39)=6.33, p<.02 ; F 2(1,50)=4.85, p<.03)$. In fact, the magnitude of the effect almost doubles $(37 \mathrm{~ms} / 71 \mathrm{~ms})$, showing that a stem primes a high frequency suffixed word more than a low one. The priming effect is smaller ( $37 \mathrm{~ms}$ ) when the target is a high frequency suffixed word than when the target is a low frequency suffixed word (71 ms).

The first thing that this experiment shows is that a stem does not prime words of its morphological family as much as these words prime themselves. This result can be interpreted as reflecting the existence of different representations for the stem as a free-standing word and the form used as the base of the other members of the morphological family (see Colé, Segui, \& Taft, 1997, for a similar proposal). This means that stem recognition is not made through a morphemic representation, or at least it is not the morphemic representation that is used to make the lexical decision. In the general discussion we propose a model which takes into account this result and those concerning the influence of the surface frequency of suffixed words.

\section{DISCUSSION}

The main findings of these two experiments concern the role of the surface frequency of suffixed word. A stem primes a high frequency suffixed word more than a low one does. However, a low frequency suffixed word primes its stem more than a high one does. First, we must emphasize that no existing models can account for these results. However, this asymmetrical pattern can be explained by postulating — as suggested earlier — two different lexical representations for some members of a morphological family: namely the stem and the high frequency derived words. When these words are processed, both representations - the full form and the decomposed form-are acti- 
vated, but in the unprimed condition it is the full form representation that allows recognition of the target word. The decomposed representation would be shared by all members of a morphological family. This representation would correspond to the stem with all the different stem + affix combinations. Within this morphemic representation, the different affixed combinations would be organized on the basis of their surface frequency (Meunier \& Segui, 1999). However, for the stem and for the high frequency suffixed words, the full form representation would underlie recognition in the unprimed condition. However, in cases where the morphemic representation is already activated - as when a low frequency suffixed word has been recognized-this representation could be used in subsequent processing. This means that when a high frequency suffixed word is presented as a prime it will be recognized through its own representation, so the subsequent recognition of the stem would just profit from a spreading activation between the different representations of a given morphological family. When a low frequency suffixed word is heard as a prime, however, the morphemic representation is activated and the stem is recognized faster because the recognition is made through the morphemic representation. When a stem is heard as a prime, it will be recognized through its own representation spreading activation to the other representations of the members of the same morphological family. In this way, a high frequency word can be recognized through its own representation, but a low frequency word must be recognized through the morphemic representation. This morphemic representation is hierarchically organized on the basis of the surface frequency of the different members, so low frequency derived words would see their recognition slowed down.

In summary, to explain the results obtained in the experiments presented in this paper we propose, on the one hand, that members of a given morphological family share a common decomposed morphological representation and, on the other hand, that some members of the family (i.e., free stems and high surface frequency affixed members) are also represented in a whole word form.

\section{REFERENCES}

Butterworth, B. 1983. Lexical representation. In B. Butterworth (Ed.), Language Production (Vol. 2, pp. 257-294). San Diego, CA: Academic Press.

Colé, P., Segui, J., \& Taft, M. 1997. Words and morphemes as units for lexical access. Journal of Memory and Language, 37, 312-330.

Drews, E. 1996. Morphological priming. In F. Grosjean and U. Frauenfelder (Eds.), A guide to spoken word recognition paradigms, Special Issue of Language and Cognitive Processes, 11(6), 629-634.

Fowler, C. A., Napps, S. E., \& Feldman, L. B. 1985. Relations among regularly and irregularly morphologically related words in the lexicon as revealed by repetition priming. Memory and Cognition, 13, 241-255. 
Frauenfelder, U., \& Schreuder, R. 1992. Constraining psycholinguistic models of morphological processing and representation: The role of productivity. In G. Booij and J. van Marle (Eds.), Yearbook of morphology 1991 (pp. 165-183). Dordrecht: Kluwer Academic.

Kempley, M., \& Morton, J. 1982. The effects of priming with regularly and irregularly related words in auditory word recognition. British Journal of Psychology, 73, 441-454.

Laudanna, A., Badecker, W., \& Caramazza, A. 1989. Priming homographic stems. Journal of Memory and Language, 28, 531-546.

Laudanna, A., \& Burani, C. 1985. Address mechanisms to decomposed lexical entries. Linguistics, 23, 775-792.

Marslen-Wilson, W. D., Tyler, L. K., Waksler, R., \& Older, L. 1994. Morphology and meaning in the English mental lexicon. Psychological Review, 101, 3-33.

McQueen, J., \& Cutler, A. 1998. Morphology in word recognition. In A. Spencer, and A. Zwicky (Eds.), The Handbook of Morphology (pp. 406-428). Oxford: Blackwell.

Meunier, F., \& Segui, J. 1999. Frequency effects in auditory word recognition: The case of suffixed words. Journal of Memory and Language (in press).

Schreuder, R., \& Baayen, R. H. 1995. Modelling morphological processing. In L. B. Feldman (Ed.), Morphological aspects of language processing (pp. 131-156). Hillsdale, NJ: Erlbaum.

Taft, M., \& Forster, K. I. 1975. Lexical storage and retrieval of prefixed words. Journal of Verbal Learning and Verbal Behavior, 14, 638-647. 